\title{
Nonlinear Optical Properties of Porphyrin, Fullerene and Ferrocene Hybrid Materials
}

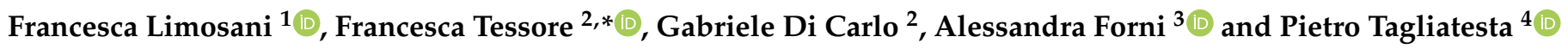 \\ 1 Photonics Micro and Nanostructures Laboratory, Physical Technologies for Safety and Health Division, \\ Fusion and Technologies for Nuclear Safety and Security Department, ENEA C.R. Frascati, Via E. Fermi 45, \\ Frascati, 00044 Rome, Italy; francesca.limosani@enea.it \\ 2 Department of Chemistry, University of Milan, INSTM Research Unit, Via C. Golgi 19, 20133 Milan, Italy; \\ gabriele.dicarlo@unimi.it \\ 3 CNR-SCITEC, Istituto di Scienze e Tecnologie Chimiche "G. Natta", c/o University of Milan, Via Golgi 19, \\ 20133 Milan, Italy; alessandra.forni@scitec.cnr.it \\ 4 Department of Chemical Science and Technologies, University of Rome "Tor Vergata", Via della Ricerca \\ Scientifica 1, 00133 Rome, Italy; pietro.tagliatesta@uniroma2.it \\ * Correspondence: francesca.tessore@unimi.it; Tel.: +39-025-031-4398
}

Citation: Limosani, F.; Tessore, F.; Di Carlo, G.; Forni, A.; Tagliatesta, P. Nonlinear Optical Properties of Porphyrin, Fullerene and Ferrocene Hybrid Materials. Materials 2021, 14 , 4404. https://doi.org/10.3390/ ma14164404

Academic Editor: Xunjin Zhu

Received: 12 July 2021

Accepted: 3 August 2021

Published: 6 August 2021

Publisher's Note: MDPI stays neutral with regard to jurisdictional claims in published maps and institutional affiliations.

Copyright: (C) 2021 by the authors. Licensee MDPI, Basel, Switzerland. This article is an open access article distributed under the terms and conditions of the Creative Commons Attribution (CC BY) license (https:/ / creativecommons.org/licenses/by/ $4.0 /)$.
Abstract: In this research, we investigated the second-order nonlinear optical (NLO) properties of multicomponent hybrid materials formed by meso-tetraphenylporphyrin $\mathrm{P}$ (both as free base and $\mathrm{Zn}{ }^{\mathrm{II}}$ complex), carrying in 2 or 2,12 $\beta$-pyrrolic position an electron donor ferrocene ( $\mathrm{Fc}$ ), and/or an electron acceptor fullerene (C60) moiety, connected to the porphyrin core via an ethynyl or an ethynylphenyl spacer. We measured the NLO response by the electric-field-induced second-harmonic generation (EFISH) technique in $\mathrm{CH}_{2} \mathrm{Cl}_{2}$ solution with a $1907 \mathrm{~nm}$ incident wavelength, recording for all the investigated compounds unexpected negative values of $\mu \beta_{1907}$. Since density functional theory (DFT) calculations evidenced for P-Fc dyads almost null ground state dipole moments and very low values for P-C60 dyads and Fc-P-C60 triads, our EFISH results suggested a significant contribution to $\gamma_{\text {EFISH }}$ of the purely electronic cubic term $\gamma(-2 \omega ; \omega, \omega, 0)$, which prevails on the quadratic dipolar orientational one $\mu \beta(-2 \omega ; \omega, \omega) / 5 \mathrm{kT}$, as confirmed by computational evidence.

Keywords: porphyrins; fullerene; ferrocene; nonlinear optics; hybrid materials; dyads; triads

\section{Introduction}

In the last two decades, many organic and organometallic molecular chromophores have attracted attention in the scientific community for their significant second-order NLO properties, mainly arising from push-pull structures as donor- $\pi$-delocalized spaceracceptor systems [1,2]. Among them, porphyrins and metalloporphyrins are very appealing, thanks to their thermal and chemical stability and the quite good solubility [3]. The electron-rich extended 18-electron $\pi$-conjugated core of porphyrins $(\mathrm{P})$ can act as a spacer between the donor and the acceptor group in the push-pull system [4-7], or it can itself be the donor or the acceptor part of the push-pull architecture [8-10].

The four meso, the eight $\beta$-pyrrolic, and the two axial positions allow a wide variety of chemical functionalizations, so that many different substituents can be linked to the core and to the metal center. Moreover, by changing the metal center, its oxidation state, the type of the axial ligands, the nature of the substituents at the periphery of the macrocycle, the flexibility of the synthetic process and of structural diversification can be exploited to achieve a fine-tuning of the electronic properties and a large second-order NLO response [3].

Through the electric-field-induced second-harmonic generation (EFISH) technique [11,12], the effect of the metal [13], of the nature and of the position of the substituents [8,9,14], and of the presence of aggregation phenomena in solution $[15,16]$ have been investigated in depth. Recently, also the non-negligible role of third-order contributions to the quadratic hyperpolarizability of $\mathrm{A}_{4} \beta$-substituted $\mathrm{Zn}{ }^{\mathrm{II}}$ porphyrins was highlighted [17]. 
The porphyrin core has the same structure as chlorophyll and therefore has been thoroughly studied as an efficient light harvester, for example, in dye-sensitized solar cells [18-24] or in systems conceived to reproduce the complex electron transfer reactions occurring in natural photosynthesis. In these molecular mimetics, porphyrins were coupled at first to benzoquinone [25], then benzoquinone was replaced by fullerene (C60) [26] to originate conjugates with increased excited charge-separated state lifetime, due to a faster forward electron transfer and a slower rate for the charge recombination reaction.

In this context, $\mathrm{C} 60$ has been a subject of several investigations by the scientific community, because of its unique physical and chemical properties [27-29]. The highly symmetric structure of $\mathrm{C} 60$, its ability to undergo multiple addition reactions, combined with its exceptional electron-accepting characteristics (e.g., it can accept up to six electrons) are by far the most important properties [30]. With its strong electron-accepting properties and remarkably small reorganization energy (ca. $0.23 \mathrm{eV}$ ), C60 is one of the most popular compounds incorporated into multicomponent molecular architecture to tune its optical properties to specific spectral regions of interest. By using chemical methods, the C60 moiety, acting as an electron acceptor in the ground electronic state, significantly improves the average hyperpolarizabilities in fullerene derivatives [31]. The observed enhancement is mainly due to the delocalization of charge from the electron-rich moiety to the electronpoor carbon cage, producing partially negatively charged fullerene moieties. For this reason, chemical modifications with a variety of electron-donating organic moieties have been studied [32].

Many other porphyrin-C60 dyads (P-C60) have been reported [33], with C60 linked through an amide bridge to the porphyrin meso-phenyl ring [34] or to the $\beta$-pyrrolic position of the core in various fashion [35-37].

The continuous interest in the realization of complex architectures with a long lifetime of charge-separated state has led research groups to perform extensive studies on different linear multi-porphyrin-fullerene adducts, some equipped with an additional moiety, mainly ferrocene $(\mathrm{Fc})$ [38-42]. Because of the low oxidation potential of the iron atom, Fc displays electron-donating properties [43].

The properties of P-C60, P-Fc or Fc-P-C60 conjugates can be modified by changing the binding position (meso or $\beta$-pyrrolic) of Fc and/or C60 on the porphyrin ring or the type of connection (double or triple bond). For example, when $\mathrm{Fc}_{\mathrm{c}}$ and $\mathrm{C} 60$ are covalently linked to the phenyl groups of a $\mathrm{Zn}^{\mathrm{II}}$ complex of a meso-tetraphenylporphyrin, as in Fc-NHCO$\mathrm{ZnP}-\mathrm{NHCO}-\mathrm{C} 60$, a charge separation lifetime of $8 \mu$ s is observed [33], which becomes two orders of magnitude higher when $\mathrm{Fc}$ and $\mathrm{C} 60$ are connected to the porphyrin core by imidazole linkers through the $\beta, \beta^{\prime}$-pyrrolic positions [44].

Binding of Fc moiety to the $\beta$-pyrrolic position of $P$ through an ethynyl group is an effective way to enhance the electronic interaction between the $\pi$-system of the macrocycle and the organometallic moiety [45]. On the other hand, the introduction of an additional phenyl spacer between Fc and P provides only a small effect, as revealed by both spectroscopic and electrochemical measurements [45].

The connection of $\mathrm{C} 60$ to the $\beta$-pyrrolic position of $\mathrm{P}$ by an ethynylphenyl bridge produces an efficient donor-acceptor system, where the lowest unoccupied and the highest occupied molecular orbitals (LUMO and HOMO) are localized on P and on C60, respectively [37].

In Fc-P-C60 triads a high charge delocalization of the $\pi$-electrons between the donor Fc and the acceptor C60 moieties is reached by linking them to the 2,12 $\beta$-pyrrolic positions of $P$ through an ethynyl or an ethynylphenyl spacer [46], thus constituting an efficient approach to the modulation of electron donor-acceptor interactions to realize hybrid materials [47-52].

Since the linkage of electron donor Fc and/or electron acceptor C60 to P turns out in Fc-P and C60-P dyads and Fc-P-C60 triads to have a push-pull structure, they might display interesting second-order NLO properties. 
Therefore, this work aims to report and discuss the results of an EFISH investigation of the dyads and triads reported in Figure 1, which have never been investigated from a nonlinear optical point of view.
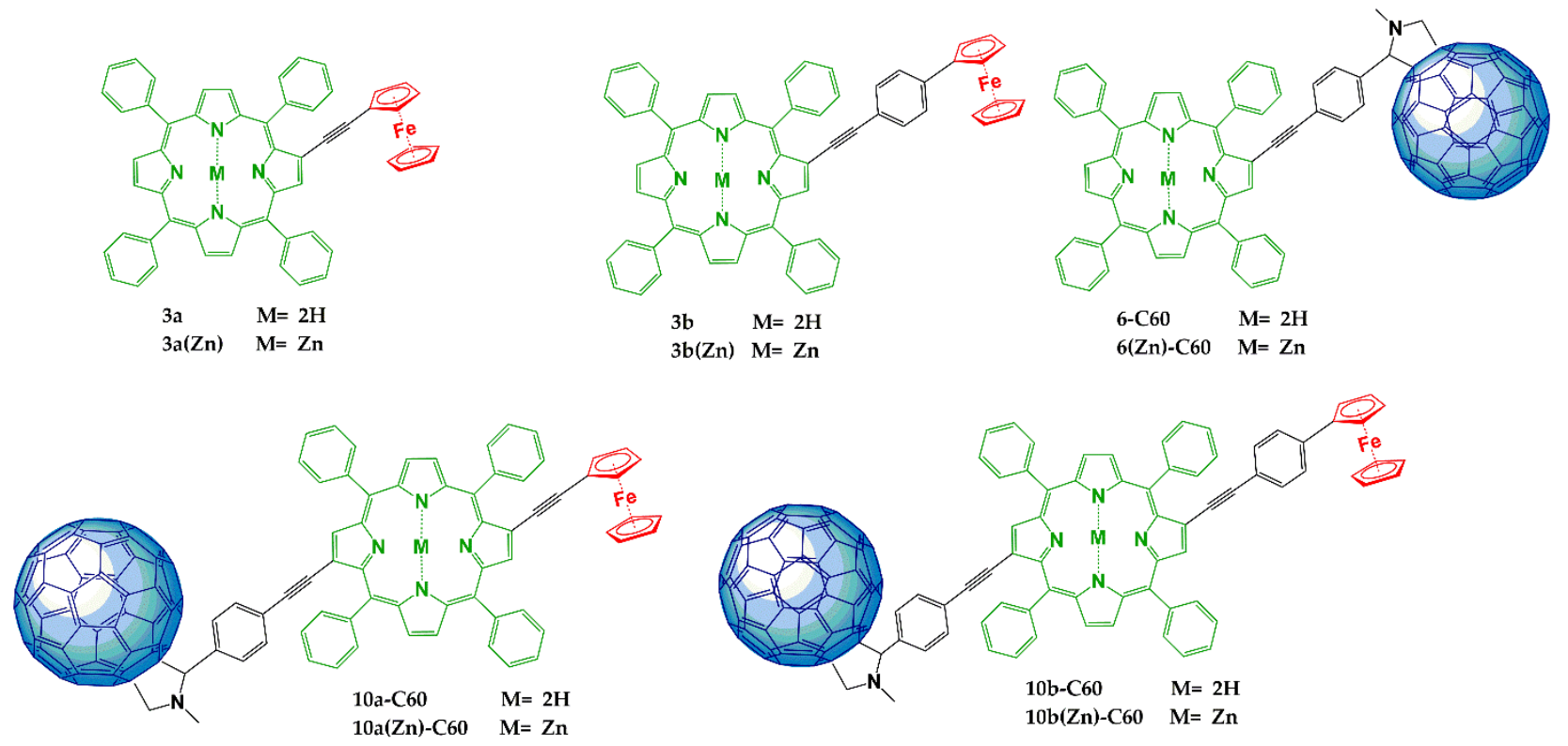

Figure 1. Investigated push-pull hybrid materials.

\section{Materials and Methods}

\subsection{Materials}

Dyads $\mathbf{3 a}, \mathbf{3 b} \mathbf{3} \mathbf{3} \mathbf{a}(\mathbf{Z n}), \mathbf{3 b}(\mathbf{Z n})$ were synthesized and characterized as reported in [53]. Dyads 6-C60 and 6(Zn)-C60 were synthetized and characterized as reported in [36]. Triads $10 a-C 60,10 a(Z n)-C 60,10 b-C 60,10 b(Z n)-C 60$ were synthetized and characterized as reported in [46]. Their NMR, MS and UV spectra were in accordance with those previously reported (see Supplementary Materials, Figures S1-S6 and S9-S16, and the elemental analyses).

Electronic absorption spectra of compounds 6-C60 and $\mathbf{6}(\mathrm{Zn})-\mathrm{C60}$ in $\mathrm{CH}_{2} \mathrm{Cl}_{2}$ solution were recorded at room temperature on a Shimadzu UV 3600 spectrophotometer (Shimadzu Corporation, Kyoto, Japan) and are reported in the Supplementary Materials (Figures S7 and S8).

\subsection{EFISH Measurements}

EFISH experiments were performed on freshly prepared $10^{-3} \mathrm{M} \mathrm{CH}_{2} \mathrm{Cl}_{2}$ solutions. The incident wavelength at $1.907 \mu \mathrm{m}$ was obtained by Raman shifting the $1.064 \mu \mathrm{m}$ emission of a Q-switched Nd:YAG laser in a high-pressure hydrogen cell (60 bar). The $1.907 \mu \mathrm{m}$ laser incident wavelength was chosen because its second harmonic (at $953 \mathrm{~nm}$ ) was far enough from the absorption bands of the chromophores in $\mathrm{CH}_{2} \mathrm{Cl}_{2}$ [46] to avoid any enhancement of the second-order NLO response because of resonance. The Maker fringe pattern (that is the harmonic intensity variation as a function of the cell translation) was obtained through a liquid cell with thick windows in the wedge configuration. In the EFISH experiments, the incident beam was synchronized with a DC field applied to the solution, with 60 and $20 \mathrm{~ns}$ pulse durations, respectively, to break its centrosymmetry. The NLO response (assumed to be real because the imaginary part was neglected) was determined from the concentration dependence of the harmonic signal with respect to that of the pure solvent through the experimental value $\gamma_{\mathrm{EFISH}}$ Equation (1):

$$
\gamma_{\mathrm{EFISH}}=\frac{\mu \beta_{\lambda}(-2 \omega ; \omega, \omega)}{5 \mathrm{kT}}+\gamma(-2 \omega ; \omega, \omega, 0) .
$$


$\gamma_{\text {EFISH }}$ is the sum of the purely electronic cubic contribution $\gamma(-2 \omega ; \omega, \omega, 0)$ and of a quadratic dipolar orientational contribution $\mu \beta_{\lambda}(-2 \omega ; \omega, \omega) / 5 \mathrm{kT}, \mu$ being the ground state dipole moment, and $\beta_{\lambda}$ the projection along the dipole moment direction of the vectorial component $\beta_{\text {vec }}$ of the tensorial quadratic hyperpolarizability working with the incident wavelength $\lambda$.

The EFISH experiments were performed recording firstly the second-order response of the pure solvent, then the second-order response of the chromophore in solution, and finally the second-order response of the solvent again. The EFISH values reported were the average of 12 consecutive measurements performed on the same sample. The uncertainty of the measure was about $\pm 15 \%$.

All the experimental EFISH $\beta_{1.907}$ values were defined according to the "phenomenological" convention [54].

The apparatus for the EFISH measurements was a prototype made by SOPRA (Paris, France) and the experiments were carried out in the Department of Chemistry of the University of Milano (Italy).

\subsection{Computational Details}

Density functional theory (DFT) calculations were performed on all compounds using the Gaussian16 suite of programs [55]. Geometry optimizations were performed with the 6-311G(d) basis set using the PBE0 functional [56,57] in $\mathrm{CH}_{2} \mathrm{Cl}_{2}$, adopting the polarized continuum model in its integral equation formalism (IEFPCM) to describe the solvent effect [58]. Using the same basis set, the SHG first hyperpolarizabilities, i.e., the $\beta(-2 \omega ; \omega, \omega)$ tensors, were computed within the coupled perturbed Kohn-Sham (CPKS) approach at the same frequency $(1907 \mathrm{~nm})$ used in the EFISH experiments. The SHG second hyperpolarizabilities, i.e., the $\gamma(-2 \omega ; \omega, \omega, 0)$ tensors, were evaluated by finite field technique. $\beta$ and $\gamma$ calculations were performed by using the M06-2X functional [59], owing to its optimal performance in reproducing hyperpolarizability values for midsize chromophores [60]. A pruned $(99,590)$ grid was selected for computation and use of two-electron integrals and their derivatives. From the full tensors $\beta$ and $\gamma$, the scalar quantities $\beta_{\mid}$, and $\gamma_{\mid l}$, respectively, were derived to get a meaningful comparison with the experimental data. $\beta_{\mid} \mid$corresponds to $3 / 5$ times $\beta_{\lambda}$, the projection along the dipole moment direction of the vectorial component of the $\beta$ tensor, that is, $\beta_{\mid \text {I }}=(3 / 5) \sum_{i}\left(\mu_{i} \beta_{i}\right) / \mu$, where $\beta_{\mathrm{i}}=(1 / 5) \sum_{\mathrm{j}}\left(\beta_{\mathrm{ijj}}+\beta_{\mathrm{jij}}+\beta_{\mathrm{jji}}\right)[61,62]$.

$\gamma_{1 \mid}$ is related to the tensor components according to the following: $\gamma_{1 \mid}=(1 / 15)$ $\left[3\left(\gamma_{\mathrm{xxxx}}+\gamma_{\mathrm{yyyy}}+\gamma_{\mathrm{zzzz}}\right)+2\left(\gamma_{\mathrm{xxyy}}+\gamma_{\mathrm{xxzz}}+\gamma_{\mathrm{yyzz}}+\gamma_{\mathrm{yyxx}}+\gamma_{\mathrm{zzxx}}+\gamma_{\mathrm{zzyy}}\right)+\left(\gamma_{\mathrm{xyyx}}+\gamma_{\mathrm{xzzx}}+\right.\right.$ $\left.\left.\gamma_{\mathrm{yzzy}}+\gamma_{\mathrm{yxxy}}+\gamma_{\mathrm{zxxz}}+\gamma_{\mathrm{zyyz}}\right)\right][61]$

\section{Results and Discussion}

\subsection{Synthesis}

The dyads and triads investigated in this work have never been considered for nonlinear optics. They have been synthesized and characterized according to the literature, as highlighted in Section $2.1[36,46,53]$.

However, since their preparation was not trivial, we summarized the main synthetic details (Scheme 1).

The possibility of placing different substituents at the $\beta$-pyrrole positions constituted a powerful approach toward the fine-tuning of tetrapyrroles and the modulation of electron donor-acceptor interactions to realize performing hybrid materials.

In Scheme 1 we show three different synthetic strategies for creating push-pull systems formed by a combination of electron donors (i.e., ferrocene), light harvester (i.e., porphyrin), and electron acceptors (i.e., C60) connected to each other through "molecular wires" of variable lengths. 


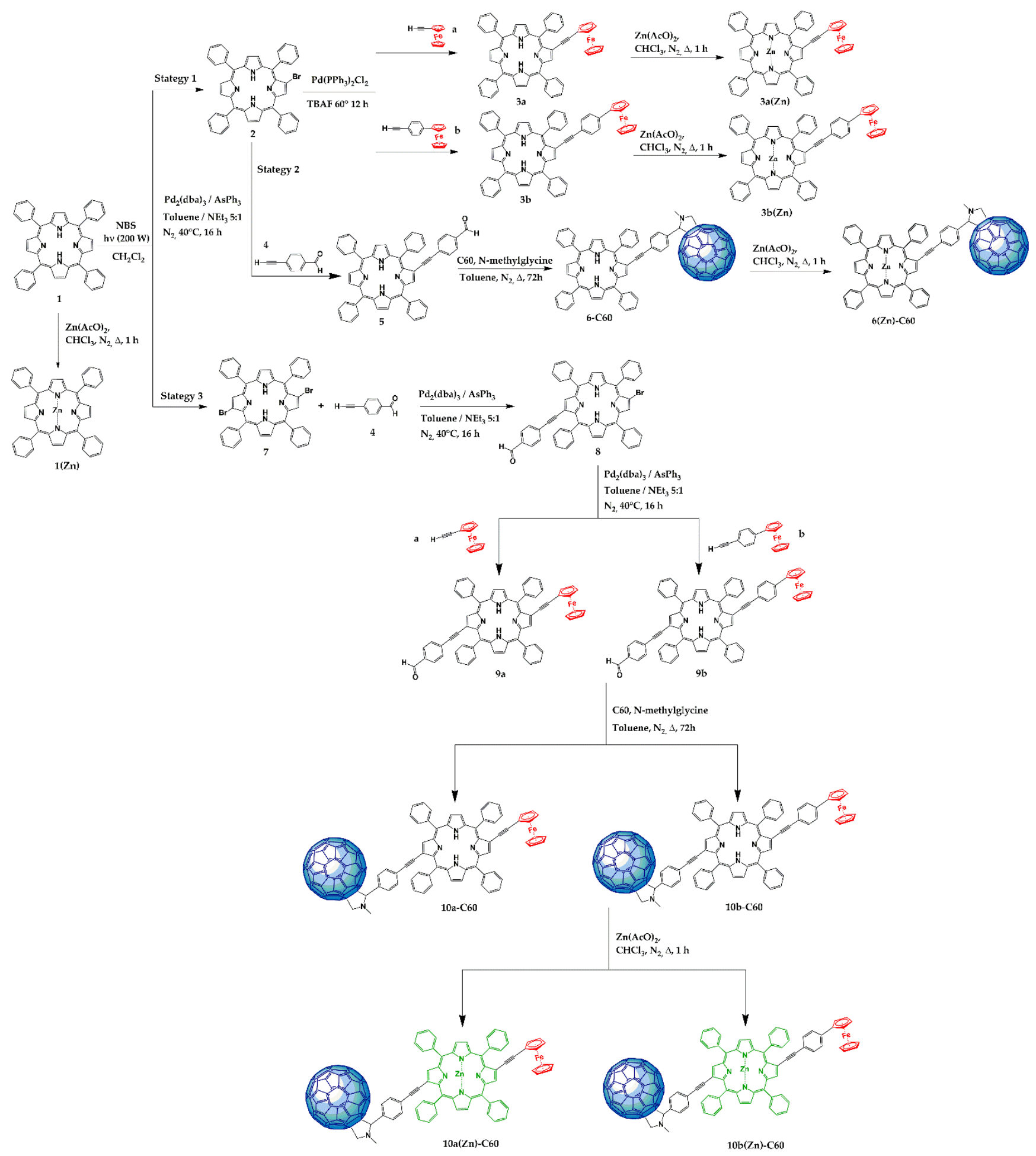

Scheme 1. Different synthetic routes toward push-pull hybrid materials.

Specifically, ethynyl or ethynylphenyl functionalities were selected as molecular bridges because of their synthetic versatility and their outstanding physicochemical properties. It was previously reported that these linkers assist in a good conduction of the charges due to their high electron density and the extended $\pi$-system [63-65].

The use of synthetic approaches that involved the Sonogashira reaction or its modification for the formation of carbon-carbon bonds allowed obtaining final mono and disubstituted compounds in $\beta$-positions of the macrocycle. 
The first step involved the bromination of compound 1 using different quantities of $\mathrm{N}$ bromosuccinimide (NBS) to obtain preferentially monobromo-(2) and dibromo-porphyrin (7). The bromination of specific antipodal pyrrole position 2 and 2,12 was carried out following the procedure from the literature [66], using light-induced reaction and $\mathrm{NBS}$ in $\mathrm{CH}_{2} \mathrm{Cl}_{2}$. The first synthetic strategy (Strategy 1) consisted of a variation of Sonogashira coupling introduced by $\mathrm{Li}$ and coworkers [67] for the formation of monosubstituted compounds by linking different donor units.

Specifically, we used ferrocenyl moieties of variable length such as ethynylferrocene (a) or 4-(ferrocenyl)-phenylacetylene (b) to functionalize the $\beta$ positions of the macrocycle in one step.

The approach was based on the use of tetrabutylammonium fluoride (TBAF) as reagent under copper-, amine-, and solvent-free conditions. We obtained the final compounds $3 \mathbf{a}$ and $3 \mathbf{b}$ in $50-65 \%$ of yield [53], starting from compound 2 and using $\mathrm{Pd}\left(\mathrm{PPh}_{3}\right)_{2} \mathrm{Cl}_{2}$ as catalyst.

The second strategy (Strategy 2) involved a Sonogashira coupling, using the catalytic system $\mathrm{Pd}_{2}(\mathrm{dba})_{3} / \mathrm{AsPh}_{3}$ developed by Lindsey and coworkers [68-70], paying particular attention to the deoxygenation and dilution conditions and, most of all, avoiding the use of copper iodide as cocatalyst.

In this way the homocoupling side reaction between terminal alkynes was suppressed, and the desired final hybrid materials were formed by the combination of porphyrin and fullerene as acceptor unit.

In this synthetic strategy the Sonogashira coupling of compound 2 with 1.5 equivalents of $p$-ethynylbenzaldehyde (4) afforded porphyrin 5. For the functionalization of $\mathrm{C} 60$ with intermediate 5, we used the Prato-Maggini reaction [71] to achieve the final compound 6-C60 in $60 \%$ of yield [36].

To obtain disubstituted hybrid materials formed in the same structure by an acceptor and donor units, the third synthetic strategy was adopted (Strategy 3).

In addition, in this case the first step involved a Sonogashira coupling of compound 7 with 1.5 equivalents of compound 4 to obtain compound 8 .

The next step was again a Sonogashira coupling reaction between compound $\mathbf{8}$ and two equivalents of different ferrocene units $(\mathbf{a}-\mathbf{b})$ to afford the corresponding intermediates $9 a$ and $9 b$.

The obtained compounds $\mathbf{9 a}$ and $\mathbf{9 b}$ were subsequently used for the cycloaddition reaction with C60 [63], affording the desired 10a-C60 and 10b-C60 systems in 41 and 35\% of yield, respectively [46].

In the final step of the different synthetic strategies, the respective $\mathrm{Zn}{ }^{\mathrm{II}}$ porphyrinate complexes of all compounds $(\mathbf{1}, 3 \mathbf{a}, \mathbf{3 b}, \mathbf{6 - C 6 0}, \mathbf{1 0 a}-\mathbf{C 6 0}, \mathbf{1 0 b}-\mathrm{C} 60)$ were obtained by dissolving the compounds in chloroform and adding a slight excess of a saturated $\mathrm{Zn}(\mathrm{OAc})_{2}$ methanol solution to yield $1(\mathrm{Zn})$, 3a(Zn), 3b(Zn), 6(Zn)-C60, $10 a(\mathrm{Zn})-\mathrm{C} 60$ and $10 \mathrm{~b}(\mathrm{Zn})-$ C60 quantitatively.

\subsection{UV-Vis Spectroscopy}

The electronic properties of the dyads and triads were investigated by UV-Vis spectroscopy in $\mathrm{CH}_{2} \mathrm{Cl}_{2}$ solution (Table 1). While the spectra of 6-C60 and $\mathbf{6}(\mathrm{Zn})-\mathrm{C60}$ were recorded for the first time (Figures S7 and S8 in the Supplementary Materials), those of the other compounds have already been reported [37,46,53]. 
Table 1. Synopsis of the UV-Vis spectroscopic data in $\mathrm{CH}_{2} \mathrm{Cl}_{2}$ of the investigated dyads and triads.

\begin{tabular}{|c|c|c|c|c|c|}
\hline Compound & $\begin{array}{c}\text { Soret Band } \\
\lambda_{\max }(\mathrm{nm}) \\
(\log \varepsilon)\end{array}$ & $\begin{array}{c}Q_{\text {IV }} \text { Band } \\
\lambda_{\max }(\mathrm{nm}) \\
(\log \varepsilon)\end{array}$ & $\begin{array}{c}Q_{\text {III }} \text { Band } \\
\lambda_{\max }(\mathrm{nm}) \\
(\log \varepsilon)\end{array}$ & $\begin{array}{c}\mathrm{Q}_{\mathrm{II}} \text { Band } \\
\lambda_{\max }(\mathrm{nm}) \\
(\log \varepsilon)\end{array}$ & $\begin{array}{c}\mathrm{Q}_{\mathrm{I}} \text { Band } \\
\lambda_{\max }(\mathrm{nm}) \\
(\log \varepsilon)\end{array}$ \\
\hline $3 a$ & $\begin{array}{c}426 \\
(5.30)\end{array}$ & $\begin{array}{c}526 \\
(4.22)\end{array}$ & $\begin{array}{c}566 \\
(3.93)\end{array}$ & $\begin{array}{c}602 \\
(3.95)\end{array}$ & $\begin{array}{c}660 \\
(3.56)\end{array}$ \\
\hline $3 a(Z n)$ & $\begin{array}{c}432 \\
(4.50)\end{array}$ & & $\begin{array}{c}566 \\
(4.08)\end{array}$ & $\begin{array}{c}602 \\
(3.83)\end{array}$ & \\
\hline $3 b$ & $\begin{array}{c}427 \\
(5.28)\end{array}$ & $\begin{array}{c}526 \\
(4.29)\end{array}$ & $\begin{array}{c}563 \\
(3.94)\end{array}$ & $\begin{array}{c}601 \\
(3.79)\end{array}$ & $\begin{array}{c}658 \\
(3.51)\end{array}$ \\
\hline $3 b(Z n)$ & $\begin{array}{c}436 \\
(5.43)\end{array}$ & & $\begin{array}{c}565 \\
(4.37)\end{array}$ & $\begin{array}{c}601 \\
(4.06)\end{array}$ & \\
\hline 6-C60 & $\begin{array}{c}427 \\
(5.31)\end{array}$ & $\begin{array}{c}522 \\
(4.27)\end{array}$ & $\begin{array}{c}558 \\
(3.83)\end{array}$ & $\begin{array}{c}599 \\
(3.76)\end{array}$ & $\begin{array}{c}656 \\
(3.42)\end{array}$ \\
\hline 6(Zn)-C60 & $\begin{array}{c}434 \\
(5.28)\end{array}$ & & $\begin{array}{c}560 \\
(4.15)\end{array}$ & $\begin{array}{c}598 \\
(4.00)\end{array}$ & \\
\hline $10 \mathrm{a}-\mathrm{C} 60$ & $\begin{array}{c}434 \\
(5.15)\end{array}$ & $\begin{array}{c}527 \\
(4.59)\end{array}$ & $\begin{array}{c}580 \\
(3.81)\end{array}$ & $\begin{array}{c}616 \\
(3.61)\end{array}$ & $\begin{array}{c}670 \\
(3.71)\end{array}$ \\
\hline $10 a(Z n)-C 60$ & $\begin{array}{c}449 \\
(5.36)\end{array}$ & & $\begin{array}{c}574 \\
(4.37)\end{array}$ & $\begin{array}{c}613 \\
(4.34)\end{array}$ & \\
\hline $10 b-C 60$ & $\begin{array}{c}435 \\
(5.23) \\
\end{array}$ & $\begin{array}{c}532 \\
(4.37) \\
\end{array}$ & $\begin{array}{c}574 \\
(4.21) \\
\end{array}$ & $\begin{array}{c}609 \\
(4.00) \\
\end{array}$ & $\begin{array}{c}666 \\
(3.68) \\
\end{array}$ \\
\hline $10 \mathrm{~b}(\mathrm{Zn})-\mathrm{C} 60$ & $\begin{array}{c}438 \\
(5.20)\end{array}$ & & $\begin{array}{c}570 \\
(3.76)\end{array}$ & $\begin{array}{c}612 \\
(3.61)\end{array}$ & \\
\hline 1 & $\begin{array}{c}417 \\
(5.58)\end{array}$ & $\begin{array}{c}515 \\
(4.19)\end{array}$ & $\begin{array}{c}550 \\
(3.83)\end{array}$ & $\begin{array}{c}591 \\
(3.68)\end{array}$ & $\begin{array}{c}647 \\
(3.61)\end{array}$ \\
\hline $1(\mathrm{Zn})$ & $\begin{array}{c}420 \\
(5.78)\end{array}$ & & $\begin{array}{c}548 \\
(4.41)\end{array}$ & $\begin{array}{c}589 \\
(3.76)\end{array}$ & \\
\hline
\end{tabular}

The UV-Vis spectra of the free-base porphyrins (3a, 3b, 6-C60, 10a-C60 and 10b-C60) and of their $\mathrm{Zn}^{\mathrm{II}}$ complexes (3a(Zn), 3b(Zn), 6(Zn)-C60, 10a(Zn)-C60 and 10b(Zn)-C60) fulfilled the "four orbital model" developed by Gouterman [72]. The $\mathrm{S}_{0} \rightarrow \mathrm{S}_{2}$ (ground $\rightarrow$ second excited state) transition produced the intense (loge in the range 4.50-5.43) Soret or B band at $420-450 \mathrm{~nm}$, and the $\mathrm{S}_{0} \rightarrow \mathrm{S}_{1}$ (ground $\rightarrow$ first excited state) transitions led to four (for free bases) or two (for the $\mathrm{Zn}^{\mathrm{II}}$ complexes) weaker ( $\log \varepsilon$ in the range 3.42-4.50) $\mathrm{Q}$ bands at $520-670 \mathrm{~nm}$. The reduction of the number of the $Q$ bands by complexation was because of the increased degree of microsymmetry, from $D_{2 \mathrm{~h}}$ of the free base to $D_{4 \mathrm{~h}}$ of the metal complex [72].

The complexation to the metal ion induced a 3-15 $\mathrm{nm}$ bathochromic shift of the B band. A $2 \mathrm{~nm}$ redshift by complexation occurred also for the $\mathrm{Q}_{\text {III }}$ band of dyads $3 \mathbf{b}$ and 6-C60. On the other hand, by complexation to $\mathrm{Zn}^{\mathrm{II}}$ of triads $10 \mathrm{a}-\mathrm{C} 60$ and $\mathbf{1 0 b}-\mathrm{C} 60$ the $\mathrm{Q}_{\mathrm{III}}$ band underwent a 4-6 nm ipsochromic shift and increased in intensity.

The UV-Vis data allowed us to highlight the effect that the introduction of $F_{c}$ and/or C60 may have had on the electronic properties of $\mathrm{P}$ (and of its $\mathrm{Zn}^{\mathrm{II}}$ complex) [73].

Starting from 5, 10, 15, 20-tetraphenylporphyrin 1 (Scheme 1), the introduction in $\beta$-pyrrolic position of an electron-donating $F_{C}$ moiety connected to the core by a triple bond (3a) produced a sizable redshift of the $B$ and the $Q$ bands (9 and 11-18 nm, respectively), suggesting an increased molecular conjugation. Conversely, the introduction in $3 \mathbf{a}$ of an additional phenyl unit between $\mathrm{Fc}$ and $\mathrm{P}(\mathbf{3} \mathbf{b})$ slightly affected the spectroscopic properties: the $B$ and $Q_{I V}$ bands were almost the same, while the other three $Q$ bands experienced a slight ipsochromic shift $(1-3 \mathrm{~nm})$. Hence, the insertion of the phenyl moiety was not effective in further enhancing $\pi$-delocalization. 
Furthermore, linking an electron-withdrawing C60 moiety to 1 by an ethynylphenyl spacer (6-C60) led to a significant redshift of the $B$ and $Q$ bands (10 and 7-11 $\mathrm{nm}$, respectively) and to an increased conjugation. However, different from what was observed when a $-\mathrm{NO}_{2}[17]$ or a cyanoacrylic moiety $[24,65,74]$ was connected in the same fashion to a $\mathrm{Zn}^{\mathrm{II}}$-porphyrin, the $\mathrm{B}$ band of $\mathbf{6}(\mathrm{Zn})-\mathrm{C} 60$ was symmetric, without any shoulder at lower energy.

In the spectra of 6-C60 and 6(Zn)-C60 the well-defined contribution of the $\mathrm{C} 60$ unit was also present at 255 and $329 \mathrm{~nm}$, respectively [75].

Therefore, the insertion of a Fc or a C60 moiety on P affects and tunes its electronic properties, promoting a charge transfer process from the $\pi$-conjugated substituent in $\beta$ pyrrolic position to the macrocycle when the former carries an electron donor, and from the macrocycle to the $\pi$-conjugated system when this latter has an electron acceptor [17]. In other words, $\mathrm{P}$ behaves as an electron acceptor moiety when connected to electronrich Fc and as an electron donor when connected to electron acceptor C60, displaying an ambivalent role $[8,10]$.

When both Fc and C60 were bound to $P$ in 2,12 $\beta$-pyrrolic positions [76] (triads 10a$\mathrm{C} 60$ and $10 \mathrm{~b}-\mathrm{C} 60$ and their $\mathrm{Zn}^{\mathrm{II}}$ complexes), the UV-Vis data showed a further redshift of the $B$ and $Q$ bands, which was more significant for the first triad.

\subsection{EFISH Investigation of the Second-Order NLO Properties}

We measured the second-order NLO response of our compounds by the EFISH technique on $10^{-3} \mathrm{M} \mathrm{CH}_{2} \mathrm{Cl}_{2}$ solutions with a $1907 \mathrm{~nm}$ incident wavelength. The details are in the Materials and Methods Sections, and the results in Table 2.

Table 2. Experimental $\gamma_{\text {EFISH }}$ and $\mu \beta_{1907}$ values $\left(10^{-3} \mathrm{M}\right.$ solution in $\left.\mathrm{CH}_{2} \mathrm{Cl}_{2}\right)$ and theoretical dipole moments $(\mu)$ for the investigated dyads and triads.

\begin{tabular}{|c|c|c|c|}
\hline Compound & $\begin{array}{l}\mu \\
\text { (D) }\end{array}$ & $\begin{array}{c}\gamma_{\text {EFISH }} \\
\left(x \times 10^{-33} \text { esu }\right)\end{array}$ & $\begin{array}{c}\mu \beta_{1907} \\
\left(x \times 10^{-48} \text { esu }\right)\end{array}$ \\
\hline $3 a$ & 0.09 & -1.54 & -320 \\
\hline $3 a(Z n)$ & 0.19 & -3.11 & -640 \\
\hline $3 b$ & 0.49 & -1.88 & -390 \\
\hline $3 b(Z n)$ & 0.28 & -2.85 & -595 \\
\hline 6-C60 & 4.21 & -2.84 & -590 \\
\hline 6(Zn)-C60 & 4.77 & -3.47 & -720 \\
\hline $10 \mathrm{a}-\mathrm{C} 60$ & 3.82 & -7.12 & -1495 \\
\hline $10 a(Z n)-C 60$ & 4.37 & -8.08 & -1670 \\
\hline $10 \mathrm{~b}-\mathrm{C} 60$ & 3.82 & -5.19 & -1075 \\
\hline $10 b(\mathrm{Zn})-\mathrm{C} 60$ & 4.14 & -6.41 & -1330 \\
\hline
\end{tabular}

All the investigated compounds showed negative $\gamma_{\mathrm{EFISH}}$ and $\mu \beta_{1907}$ values. For dyads 6-C60 and $6(\mathrm{Zn})-\mathrm{C} 60$ and for triads $10 \mathrm{a}(\mathrm{Zn})-\mathrm{C} 60$ and $10 \mathrm{~b}(\mathrm{Zn})-\mathrm{C} 60$ this outcome was quite unexpected. Indeed, the similar complexes BP1 and BP3 (Figure 2), with a $-\mathrm{NO}_{2}$ acceptor group (instead of C60) and a $-\mathrm{NMe}_{2}$ donor group (instead of $\mathrm{Fc}$ ) linked to the core by an ethynylphenyl moiety in 2 and 2,12 $\beta$-pyrrolic position, displayed positive $\gamma_{\text {EFISH }}$ and $\mu \beta_{1907}$ values [17].

On the other hand, the negative $\gamma_{\mathrm{EFISH}}$ and $\mu \beta_{1907}$ of dyads $\mathbf{3 a}, \mathbf{3 a}(\mathbf{Z n}), \mathbf{3 b}$, and $\mathbf{3 b}(\mathbf{Z n})$ were in agreement with what was observed for $\mathrm{BP} 2$, where $\mathrm{Fc}$ was replaced by $-\mathrm{NMe}_{2}$ [17].

According to the "two-level" model developed by Oudar [77,78], a negative sign of $\mu \beta_{\lambda}$ derives from a negative value of $\Delta \mu_{\mathrm{eg}}$, which is the difference between the excited and the ground state molecular dipole moments. Negative $\mu \beta_{\lambda}$ values suggest a decrease of the excited state dipole moment in comparison to the ground state [79]. This evidence occurred for C60 containing second-order NLO chromophores, in which the C60 acceptor moiety endows a cyclopropane ring bridging an ethynylthienyl spacer linked to a trimethylsilyl or an alkynyl platinum donor unit [80]. 


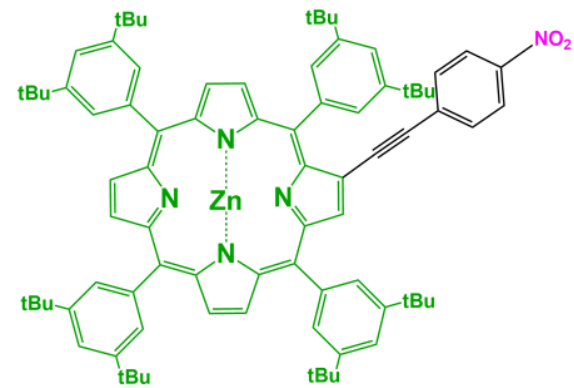

BP1

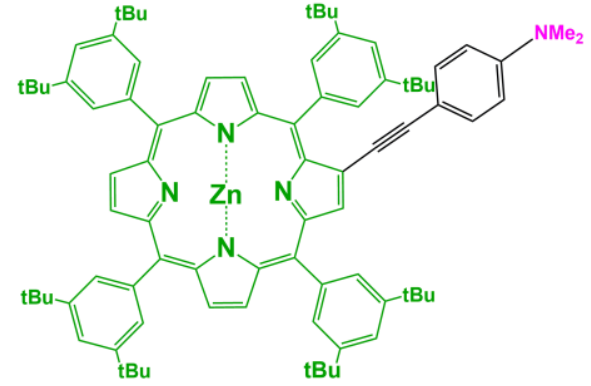

BP2

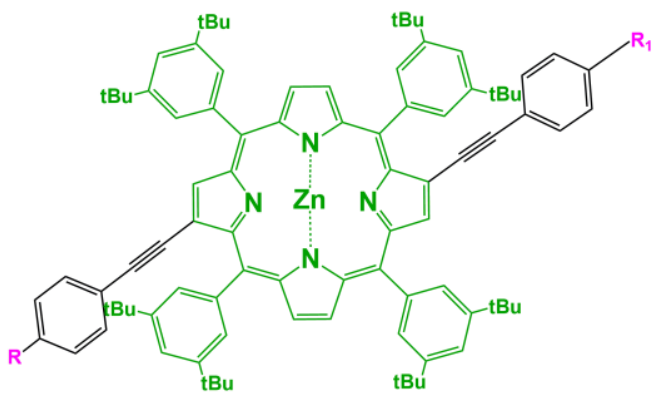

$$
\begin{array}{ll}
\text { BP3 } & \mathrm{R}=-\mathrm{NO}_{2} \quad \mathrm{R}_{1}=-\mathrm{NMe}_{2} \\
\text { BP4 } & \mathrm{R}=\mathrm{R}_{1}=-\mathrm{NO}_{2} \\
\text { BP5 } & \mathrm{R}=\mathrm{R}_{1}=-\mathrm{NMe}_{2}
\end{array}
$$

Figure 2. $\mathrm{A}_{4} \beta$-pyrrolic $\mathrm{Zn}{ }^{\mathrm{II}}$ porphyrins similar to the ones here investigated.

Moreover, when the second-order NLO response obtained by the EFISH technique showed an unexpected sign and/or absolute value of $\beta_{\lambda}$, aggregation or other molecular interactions occurring in solution should be considered [15,16].

Nevertheless, $\mathrm{A}_{4} \beta$-pyrrolic mono or disubstituted $\mathrm{Zn}{ }^{\mathrm{II}}$ porphyrins were characterized by a remarkable steric hindrance, because of the $70-90^{\circ}$ dihedral angle formed by the aryl rings in 5, 10, 15, 20 meso position with the mean plane of the macrocycle, which lowered the flatness of the molecule and hampered aggregation phenomena in solution [16,76].

The $\mu \beta_{1907}$ values in Table 2 derive from Equation (1), neglecting the cubic electronic contribution $\gamma_{0}(-2 \omega ; \omega, \omega, 0)$ to $\gamma_{\mathrm{EFISH}}$, and for this reason could be overestimated. Indeed, the EFISH technique is appropriate to study dipolar chromophores with a clear push-pull structure, for which the third-order contribution is much smaller than the quadratic dipolar orientational term and can be neglected. However, for macrocycles with an extended $\pi$ conjugation and significant third-order NLO properties (asymmetrically monosubstituted metal porphyrins [81], phtalocyanines [82] or porphyrazines [83]), the EFISH second-order NLO response could be affected by a significant error, since the cubic term is comparable, at least as an order of magnitude, to the quadratic orientational one. Moreover, as recently reported by some of us for the BP2 complex (Figure 2) [17], when the molecular ground state dipole moment $(\mu)$ is low, the electronic third-order term can have an overwhelming role, determining the sign of the second-order response.

To clarify these aspects, we computed the ground state dipole moments of our dyads and triads by DFT (Table 2).

The $\mu$ values for all the P-Fc dyads (3a, $\mathbf{3 a}(\mathbf{Z n}), \mathbf{3 b}$ and $\mathbf{3 b}(\mathbf{Z n})$ ) were almost null, suggesting for these compounds a very low dipolar character. Notably, $3 \mathbf{a}(\mathbf{Z n})$ and $3 \mathbf{b}(\mathbf{Z n})$ showed the lowest $\mu$ ever computed for $\mathrm{A}_{4} \beta$-pyrrolic monosubstituted $\mathrm{Zn}^{\mathrm{II}}$ porphyrins $[8,17]$, with values comparable in the order of magnitude only to the ones reported for symmetric structures such as BP4 and BP5 (Figure 2). Therefore, endowing the porphyrin core either as a free core or as a $\mathrm{Zn}^{\mathrm{II}}$ complex with a donor Fc moiety did not produce an efficient push-pull system, despite the increased molecular conjugation pointed out 
by the UV-Vis spectroscopic data (Table 1). In other words, the electronic perturbation induced by $\mathrm{Fc}_{\mathrm{c}}$ in the $\beta$-pyrrolic position of the macrocycle was trivial. The overall polarizability of the system increased, but without any sizable asymmetry in the electronic density distribution.

Hence, we can safely conclude that, similar to what was reported for slightly asymmetric BP2 and for symmetric BP4 and BP5 [17], in P-Fc dyads the electronic third-order contribution $\gamma_{0}(-2 \omega ; \omega, \omega, 0)$ to $\gamma_{\text {EFISH }}$ outstrips the dipolar orientational term $\mu \beta_{1907}(-2 \omega ; \omega$, $\omega) / 5 \mathrm{kT}$. Basically P-Fc dyads behave as third-order NLO chromophores, because of their almost null polarity.

This conclusion is supported by CP-DFT calculations in dichloromethane, which we chose to perform only on the $\mathrm{Zn}^{\mathrm{II}}$ dyads and triads similar to BP1, BP2 and BP3, as the most representative of our series (Table 3).

Table 3. Theoretical $\beta_{\mid}, \mu \beta_{\mid} / 5 \mathrm{kT}$ and $\gamma_{\mid}$, values of representative dyads and triads.

\begin{tabular}{cccc}
\hline Compound & $\begin{array}{c}\beta_{||} \\
\left(\mathbf{x} \times \mathbf{1 0}^{-30} \mathbf{e s u}\right)\end{array}$ & $\begin{array}{c}\mu \beta_{||} / 5 \mathbf{k T} \\
\left(\mathbf{x} \times \mathbf{1 0}^{-36} \mathbf{e s u}\right)\end{array}$ & $\begin{array}{c}\gamma_{\mid I} \\
\left(\mathbf{x} \times \mathbf{1 0}^{-36} \mathbf{e s u}\right)\end{array}$ \\
\hline 3b(Zn) & -21 & -29 & -1820 \\
$\mathbf{6 ( Z n ) - C 6 0}$ & 30 & 696 & -1543 \\
$\mathbf{1 0 b ( Z n ) - C 6 0}$ & 42 & 845 & -3225 \\
\hline
\end{tabular}

As expected, $\mathbf{3 b}(\mathbf{Z n})$ showed a very low $\beta_{||}$value as a consequence of a negligible $\mu \beta_{||} / 5 \mathrm{kT}$ in comparison to the high and negative $\gamma_{\mid,}$(Table 3).

In contrast, linking a C60 moiety to P produced dyads (6-C60 and 6(Zn)-C60) with $\mu$ values in the range 3.5-4.8 D, in agreement with a decrease of the electron density on $\mathrm{P}$ when connected to acceptor $\mathrm{C} 60$ and playing the role of the electron donor part of the pushpull system [8]. The acceptor character of $\mathrm{C} 60$ appeared lower than that of the $-\mathrm{NO}_{2}$ group, since for BP1 a $\mu$ value of $7.8 \mathrm{D}$ was computed (compared with 4.77 of 6 (Zn)-C60) [17]. Moreover, an enhancement of $\mu$ occurred by complexation (the $\mu$ of $6-\mathrm{C} 60$ was $4.21 \mathrm{D}$ and that of 6(Zn)-C60 4.77 D) [8].

Nevertheless, P-C60 dyads, albeit more polar than the P-Fc counterparts, still showed a low molecular asymmetry. In agreement with the enhanced $\mu$ value and the more pronounced push-pull character, the computed $\beta_{||}$and $\mu \beta_{||} / 5 \mathrm{kT}$ of $\mathbf{6 ( Z n ) - C 6 0}$ were higher than those of $3 \mathbf{b}(\mathbf{Z n})$, but the $\gamma_{\mathrm{EFISH}}$ was still dominated by the third-order contribution, which produced a negative sign.

Eventually, the $\mu$ values of the triads were similar one to the other and to those of P-C60 dyads, confirming the insignificant contribution of the Fc unit to the polarity of the system, even in the presence of the additional phenyl spacer between Fc and P. An increase of $\mu$ occurred by complexation (3.82 D vs. $4.37 \mathrm{D}$ for $10 \mathrm{a}-\mathrm{C} 60$ and $10 \mathrm{a}(\mathrm{Zn})-\mathrm{C} 60$ and $3.82 \mathrm{D}$ vs. $4.14 \mathrm{D}$ for $10 \mathrm{~b}-\mathrm{C} 60$ and $\mathbf{1 0 b}(\mathrm{Zn})-\mathrm{C} 60)$. Once again, the computed $\beta_{11}$, $\mu \beta_{||} / 5 \mathrm{kT}$ and $\gamma_{||}$values supported an overwhelming contribution of the cubic term to $\gamma_{\text {EFISH }}$. Moreover, the absolute value of $\gamma_{I}$ of $10 b(\mathrm{Zn})-\mathrm{C} 60$ was the highest among the series (Table 3), since the introduction of the ethynylphenyl spacer carrying the Fc moiety extended $\pi$-delocalization, as evidenced by the bathochromic shift of the B and Q bands in the UV-Vis spectra (Table 1).

\section{Conclusions}

In this work, we investigated the second-order NLO properties of a series of dyads and triads composed by meso-tetraphenylporphyrin $\mathrm{P}$ (both as free base and $\mathrm{Zn}^{\mathrm{II}}$ complex), carrying in 2 or 2,12 $\beta$-pyrrolic position an electron donor ferrocene $(\mathrm{Fc})$, and/or an electron acceptor fullerene (C60) moiety, connected to the porphyrinic core via an ethynyl or an ethynylphenyl spacer.

UV-Vis spectroscopy showed that the introduction of a Fc or a C60 unit on the P core causes a sizable bathochromic shift of the $\mathrm{B}$ and $\mathrm{Q}$ bands of the tetrapyrrolic macrocycle, pointing to an increased molecular conjugation, in particular, with an ethynyl spacer. 
Indeed, the insertion of an additional phenyl moiety between $\mathrm{Fc}_{c}$ and $\mathrm{P}$ did not enhance $\pi$-delocalization significantly. On the other hand, linking both Fc and C60 to P produced a further redshift of the electronic absorption bands.

Therefore, the presence of Fc and / or C60 tuned the electronic properties of P in such a way that it behaved as an electron acceptor when connected to electron-rich Fc and as an electron donor when connected to electron-deficient $\mathrm{C} 60$, confirming its ambivalent role $[8,10]$.

Surprisingly, EFISH measurements produced for all the investigated compounds negative $\gamma_{\mathrm{EFISH}}$ and $\mu \beta_{1907}$ values. Since $\mathrm{A}_{4} \beta$-pyrrolic mono or disubstituted $\mathrm{Zn}^{\mathrm{II}}$ porphyrins feature a sterically hindered architecture [16,76], we could safely exclude the presence of aggregation phenomena in solution, which could affect the sign and magnitude of the EFISH response.

However, when the ground state molecular dipole moment was low, the pure electronic cubic contribution to $\gamma_{\mathrm{EFISH}} \gamma_{0}(-2 \omega ; \omega, \omega, 0)$ overwhelmed the dipolar orientational term $\mu \beta_{1907}(-2 \omega ; \omega, \omega) / 5 \mathrm{kT}$, dictating the sign of the second-order response [17].

DFT-computed dipole moments of P-Fc dyads were almost null, and for P-C60 dyads and Fc-P-C60 triads they were in the range 3.5-4.8 D, suggesting for all the investigated compounds a low polarity, which led to a non-negligible third-order contribution to their second-order NLO response, as confirmed by the calculated $\beta_{||}, \mu \beta_{||} / 5 \mathrm{kT}$ and $\gamma_{||}$values of representative dyads and triads.

Therefore, our investigation proved from both an experimental and a theoretical point of view that the combination of porphyrins, fullerene, and ferrocene leads to hybrid materials with a high polarizability but a low push-pull character, whose second-order NLO properties as measured by the EFISH technique must be analyzed very carefully.

Supplementary Materials: The following are available online at https:/ /www.mdpi.com/article/10 $.3390 / \mathrm{ma1} 1164404 / \mathrm{s} 1$, Figure S1: ${ }^{1} \mathrm{H}-\mathrm{NMR}$ spectrum of compound $3 \mathbf{a}$ in $\mathrm{CDCl}_{3}$ at $300 \mathrm{~K}$ at $400 \mathrm{MHz}$, Figure S2: ${ }^{1} \mathrm{H}-\mathrm{NMR}$ spectrum of compound $3 \mathbf{a}(\mathrm{Zn})$ in $\mathrm{CDCl}_{3}$ at $300 \mathrm{~K}$ at $400 \mathrm{MHz}$, Figure S3: ${ }^{1} \mathrm{H}-$ NMR spectrum of compound $3 \mathbf{b}$ in $\mathrm{CDCl}_{3}$ at $300 \mathrm{~K}$ at $400 \mathrm{MHz}$, Figure S4: ${ }^{1} \mathrm{H}-\mathrm{NMR}$ spectrum of compound $\mathbf{3 b}(\mathbf{Z n})$ in $\mathrm{CDCl}_{3}$ at $300 \mathrm{~K}$ at $400 \mathrm{MHz}$, Figure S5: ${ }^{1} \mathrm{H}-\mathrm{NMR}$ spectrum of compound 6-C60 in $\mathrm{CDCl}_{3}$ at $300 \mathrm{~K}$ at $400 \mathrm{MHz}$, Figure S6: FAB MS spectrum of compound 6-C60 using as matrix NBA, Figure S7: UV-Vis spectrum of compound 6-C60 in $\mathrm{CH}_{2} \mathrm{Cl}_{2}$, Figure S8: UV-Vis spectrum of compound 6(Zn)-C60 in $\mathrm{CH}_{2} \mathrm{Cl}_{2}$, Figure S9: ${ }^{1} \mathrm{H}-\mathrm{NMR}$ spectrum of compound $10 \mathrm{a}-\mathrm{C} 60$ in $\mathrm{CDCl}_{3}$ at $300 \mathrm{~K}$ at $400 \mathrm{MHz}$, Figure S10: MALDI-TOF MS spectrum of compound 10a-C60 using as matrix gentisic acid, Figure S11: ${ }^{1} \mathrm{H}-\mathrm{NMR}$ spectrum of compound $\mathbf{1 0 a}(\mathbf{Z n})-\mathrm{C} 60$ in $\mathrm{CDCl}_{3}$ at $300 \mathrm{~K}$ at $400 \mathrm{MHz}$, Figure S12: MALDI-TOF MS spectrum of compound 10a-C60 using as matrix gentisic acid, Figure S13: ${ }^{1} \mathrm{H}-$ NMR spectrum of compound 10b-C60 in $\mathrm{CDCl}_{3}$ at $300 \mathrm{~K}$ at $400 \mathrm{MHz}$, Figure S14: MALDI-TOF MS spectrum of compound 10b-C60 using as matrix gentisic acid, Figure S15: ${ }^{1} \mathrm{H}-\mathrm{NMR}$ spectrum of compound $10 \mathrm{~b}(\mathrm{Zn})-\mathrm{C} 60$ in $\mathrm{CDCl}_{3}$ at $300 \mathrm{~K}$ at $400 \mathrm{MHz}$, Figure S16: MALDI-TOF MS spectrum of compound $10 \mathrm{~b}(\mathrm{Zn})-\mathrm{C} 60$ using as matrix gentisic acid.

Author Contributions: Conceptualization, P.T. and F.T.; formal analysis, A.F.; investigation, F.L. and F.T.; writing—original draft preparation, F.L. and F.T.; writing—review and editing, F.L., F.T., P.T., A.F., G.D.C.; visualization, F.L., F.T. and G.D.C. All authors have read and agreed to the published version of the manuscript.

Funding: This research received no external funding.

Institutional Review Board Statement: Not applicable.

Informed Consent Statement: Not applicable.

Acknowledgments: F.T. and G.D.C. gratefully acknowledge Regione Lombardia and Fondazione Cariplo for the use of the instrumentation purchased through the SmartMatLab Centre project (Fondazione Cariplo Grant 2013-1766) and deeply thank Stefania Righetto for technical help with the EFISH measurements. P.T. and F.L. want to thank Alessandro Leoni for his technical assistance.

Conflicts of Interest: The authors declare no conflict of interest. 


\section{References}

1. Cariati, E.; Pizzotti, M.; Roberto, D.; Tessore, F.; Ugo, R. Coordination and organometallic compounds and inorganic-organic hybrid crystalline materials for second-order non-linear optics. Coord. Chem. Rev. 2006, 250, 1210-1233. [CrossRef]

2. Di Bella, S.; Dragonetti, C.; Pizzotti, M.; Roberto, D.; Tessore, F.; Ugo, R. Coordination and organometallic complexes as second-order nonlinear optical molecular materials. Top. Organomet. Chem. 2010, 28, 1-55. [CrossRef]

3. Tessore, F.; Orbelli Biroli, A.; Di Carlo, G.; Pizzotti, M. Porphyrins for second order nonlinear optics (NLO): An intriguing history. Inorganics 2018, 6, 81-97. [CrossRef]

4. Suslick, K.S.; Chen, C.T.; Meredith, G.R.; Cheng, L.T. Push-Pull porphyrins as nonlinear optical materials. J. Am. Chem. Soc. 1992, 114, 6928-6930. [CrossRef]

5. LeCours, S.M.; Guan, H.W.; Di Magno, S.G.; Wang, C.H.; Therien, M.J. Push-pull arylethynyl porphyrins: New chromophores that exhibit large molecular first-order hyperpolarizabilities. J. Am. Chem. Soc. 1996, 118, 1497-1503. [CrossRef]

6. Yeung, M.; Ng, A.C.H.; Drew, M.G.E.; Vorpagel, E.; Breitung, E.M.; McMahon, R.J.; Ng, D.K. Facile synthesis and nonlinear optical properties of push-pull 5,15-diphenylporphyrins. J. Org. Chem. 1998, 63, 7143-7150. [CrossRef]

7. Pizzotti, M.; Annoni, E.; Ugo, R.; Bruni, S.; Quici, S.; Fantucci, P.; Bruschi, M.; Zerbi, G.; Del Zoppo, M. A multitechnique investigation of the second order NLO response of 10,20-diphenylporphyrinato nickel(II) complex carrying a phenylethynyl based push-pull system in the 5- and 15-positions. J. Porphyr. Phthalocyanines 2004, 8, 1311-1324. [CrossRef]

8. Annoni, E.; Pizzotti, M.; Ugo, R.; Quici, S.; Morotti, T.; Bruschi, M.; Mussini, P. Synthesis, electronic properties and significant second-order non-linear optical responses of meso-tetraphenylporphyrins and their $\mathrm{Zn}$ (I complexes carrying a push or pull group in the $\beta$ pyrrolic position. Eur. J. Inorg. Chem. 2005, 3857-3874. [CrossRef]

9. Morotti, T.; Pizzotti, M.; Ugo, R.; Quici, S.; Bruschi, M.; Mussini, P.; Righetto, S. Electronic characterization and significant secondorder NLO response of 10,20-diphenylporphyrins and their $\mathrm{Zn}{ }^{\mathrm{II}}$ complexes substituted in the meso position with $\pi$-delocalized linkers carrying push or pull groups. Eur. J. Inorg. Chem. 2006, 1743-1757. [CrossRef]

10. Lopez-Duarte, I.; Reeve, J.E.; Pérez-Moreno, J.; Boczarow, I.; Depotter, G.; Fleischhauer, J.; Clays, K.; Anderson, H.L. “Push-no-pull” porphyrins for second harmonic generation imaging. Chem. Sci. 2013, 4, 2024-2027. [CrossRef]

11. Levine, B.F.; Bethea, C.G. Molecular hyperpolarizabilities determined from conjugated and nonconjugated organic liquids. Appl. Phys. Lett. 1974, 24, 445-447. [CrossRef]

12. Singer, K.D.; Garito, A.F. Measurements of molecular second order optical susceptibilities using dc induced second harmonic generation. J. Chem. Phys. 1981, 75, 3572-3580. [CrossRef]

13. De Angelis, F.; Fantacci, S.; Sgamellotti, A.; Pizzotti, M.; Tessore, F.; Orbelli Biroli, A. Time-dependent and coupled-perturbed DFT and HF investigations on the absorption spectrum and nonlinear optical properties of push-pull M(II)-porphyrin complexes (M=Zn, Cu, Ni). Chem. Phys. Lett. 2007, 447, 10-15. [CrossRef]

14. Tessore, F.; Di Carlo, G.; Forni, A.; Righetto, S.; Limosani, F.; Orbelli Biroli, A. Second order nonlinear optical properties of 4-styrylpyridines axially coordinated to $\mathrm{A}_{4} \mathrm{Zn}^{\mathrm{II}}$ porphyrins: A comparative experimental and theoretical investigation. Inorganics 2020, 8, 45. [CrossRef]

15. Pizzotti, M.; Tessore, F.; Orbelli Biroli, A.; Ugo, R.; De Angelis, F.; Fantacci, S.; Sgamellotti, A.; Zuccaccia, D.; Macchioni, A. An EFISH, theoretical, and PGSE NMR investigation on the relevant role of aggregation on the second order response in $\mathrm{CHCl}_{3}$ of the push-pull chromophores [5-[[4'-(Dimethylamino)phenyl]ethynyl]-15-[(4"-nitrophenyl)ethynyl]-10,20-diphenylporphyrinate]M(II) (M=Zn, Ni). J. Phys. Chem. C 2009, 113, 11131-11141. [CrossRef]

16. Orbelli Biroli, A.; Tessore, F.; Righetto, S.; Forni, A.; Macchioni, A.; Rocchigiani, L.; Pizzotti, M.; Di Carlo, G. Intriguing influence of - $\mathrm{COOH}$-driven intermolecular aggregation and acid-base interactions with $\mathrm{N}, \mathrm{N}$-dimethylformamide on the second-order nonlinear-optical response of 5,15 push-pull diarylzinc(II) porphyrinates. Inorg. Chem. 2017, 56, 6438-6450. [CrossRef]

17. Di Carlo, G.; Pizzotti, M.; Righetto, S.; Forni, A.; Tessore, F. Electric-field-induced second harmonic generation nonlinear optic response of $\mathrm{A}_{4} \beta$-pyrrolic-substituted $\mathrm{Zn}{ }^{\mathrm{II}}$ porphyrins: When cubic contributions cannot be neglected. Inorg. Chem. 2020, 59, 7561-7570. [CrossRef]

18. Li, L.L.; Diau, E.W.G. Porphyrin-sensitized solar cells. Chem. Soc. Rev. 2013, 42, 291-304. [CrossRef]

19. Mathew, S.; Yella, A.; Gao, P.; Humphry-Baker, R.; Curchod, B.F.E.; Ashari-Astani, N.; Tavernelli, I.; Rothlisberger, U.; Nazeeruddin, M.K.; Grätzel, M. Dye-sensitized solar cells with $13 \%$ efficiency achieved through the molecular engineering of porphyrin sensitizers. Nat. Chem. 2014, 6, 242-247. [CrossRef]

20. Lu, J.; Liu, S.; Wang, M. Push-pull porphyrins as light-harvesters for efficient dye-sensitized solar cells. Front. Chem. 2018, 6, 541. [CrossRef]

21. Di Carlo, G.; Orbelli Biroli, A.; Tessore, F.; Pizzotti, M.; Mussini, P.R.; Amat, A.; De Angelis, F.; Abbotto, A.; Trifiletti, V.; Ruffo, R. Physicochemical investigation of the panchromatic effect on $\beta$-substituted $\mathrm{Zn}^{\mathrm{II}}$ porphyrinates for DSSCs: The role of the $\pi$ bridge between a dithienylethylene unit and the porphyrinic ring. J. Phys. Chem. C 2014, 118, 7307-7320. [CrossRef]

22. Covezzi, A.; Orbelli Biroli, A.; Tessore, F.; Forni, A.; Marinotto, D.; Biagini, P.; Di Carlo, G.; Pizzotti, M. 4D- $\pi$ - 1 A type $\beta$-substituted $\mathrm{Zn}{ }^{\mathrm{II}}$-porphyrins: Ideal green sensitizers for building-integrated photovoltaics. Chem. Commun. 2016, 52, 12642-12645. [CrossRef]

23. Colombo, A.; Di Carlo, G.; Dragonetti, C.; Magni, M.; Orbelli Biroli, A.; Pizzotti, M.; Roberto, D.; Tessore, F.; Benazzi, E.; Bignozzi, C.A.; et al. Coupling of zinc porphyrin dyes and copper electrolytes: A springboard for novel sustainable dye-sensitized solar cells. Inorg. Chem. 2017, 56, 14189-14197. [CrossRef] [PubMed] 
24. Di Carlo, G.; Orbelli Biroli, A.; Pizzotti, M.; Tessore, F. Efficient sunlight harvesting by $\mathrm{A}_{4} \beta$-pyrrolic substitued $\mathrm{Zn}^{\mathrm{II}}$ porphyrins: A mini-review. Front. Chem. 2019, 7, 177. [CrossRef] [PubMed]

25. Antolovic, M.; Keyte, P.J.; Oliver, A.M.; Paddon-Row, M.N.; Kroon, J.; Verhoeven, J.W.; Jonker, S.A.; Warman, J.M. Modeling long-range photosynthetic electron transfer in rigidly bridged porphyrin-quinone systems. J. Phys. Chem. 1991, 95, 1933-1941. [CrossRef]

26. Bell, T.D.M.; Smith, T.A.; Ghiggino, K.P.; Ranasinghe, M.G.; Shephard, M.J.; Paddon-Row, M.N. Long-lived photoinduced charge separation in a bridged $\mathrm{C}_{60}$-porphyrin dyad. Chem. Phys. Lett. 1997, 268, 223-228. [CrossRef]

27. Guldi, D.M.; Kamat, P.V. Photophysical properties of pristine fullerenes, functionalized fullerenes, and fullerene-containing donor-bridge acceptor systems. In Fullerenes: Chemistry, Physics, and Technology, 1st ed.; Kadish, K.M., Ruoff, R.S., Eds.; John Wiley \& Sons Inc.: New York, NY, USA, 2000; pp. 225-281.

28. Armaroli, N. Photoinduced energy transfer processes in functionalized fullerenes. In Fullerenes: From Synthesis to Optoelectronic Properties, 1st ed.; Guldi, D.M., Martin, N., Eds.; Springer: Dordrecht, Switzerland, 2002; Volume 4, pp. $137-162$.

29. Signorini, R.; Bozio, R.; Prato, M. Optical limiting applications. In Fullerenes: From Synthesis to Optoelectronic Properties, 1st ed.; Guldi, D.M., Martin, N., Eds.; Springer: Dordrecht, Switzerland, 2002; Volume 4, pp. 295-326.

30. Echegoyen, L.; Diederich, F.; Echegoyen, L.E. Electrochemistry of fullerenes. In Fullerenes: Chemistry, Physics, and Technology, 1st ed.; Kadish, K.M., Ruoff, R.S., Eds.; John Wiley \& Sons Inc.: New York, NY, USA, 2000; pp. 1-51.

31. Loboda, O.; Zalesny, R.; Avramopoulos, A.; Luis, J.M.; Kirtman, B.; Tagmatarchis, N.; Reis, H.; Papadopoulos, M.G. Linear and nonlinear optical properties of [60]fullerene derivatives. J. Phys. Chem. A 2009, 113, 1159-1170. [CrossRef] [PubMed]

32. Prato, M. [60]Fullerene chemistry for materials science applications. J. Mater. Chem. 1997, 7, 1097-1109. [CrossRef]

33. Guldi, D.M. Fullerene-porphyrin architectures; photosynthetic antenna and reaction center models. Chem. Soc. Rev. 2002, 31, 22-36. [CrossRef]

34. Imahori, H.; Hagiwara, K.; Aoki, M.; Akiyama, T.; Taniguchi, S.; Okada, T.; Shirakawa, M.; Sakata, Y. Linkage and solvent dependence of photoinduced electron transfer in zincporphyrin- $\mathrm{C}_{60}$ dyads. J. Am. Chem. Soc. 1996, 118, 11771-11782. [CrossRef]

35. Reed, C.A.; Boyd, P.; Drovetskaya, T. A fullerene porphyrin conjugate. Tetrahedron Lett. 1995, 36, 7971-7974. [CrossRef]

36. Lembo, A.; Tagliatesta, P.; Guldi, D.M. Synthesis and photophysical investigation of new porphyrin derivatives with $\beta$-pyrrole ethynyl linkage and corresponding dyad with [60]fullerene. J. Phys. Chem. A 2006, 110, 11424-11434. [CrossRef]

37. Lembo, A.; Tagliatesta, P.; Guldi, D.M.; Wielopolski, M.; Nuccettelli, M. Porphyrin- $\beta$-oligo-ethynylenephenylene-[60]fullerene triads: Synthesis and electrochemical and photophysical characterization of the new porphyrin-oligo-PPE-[60]fullerene systems. J. Phys. Chem. A 2009, 113, 1779-1793. [CrossRef]

38. Imahori, H.; Sakata, Y.; Nishimura, Y.; Yamazaki, I. Synthesis and photophysical properties of a diporphyrin-fullerene triad. Chem. Commun. 1999, 625-626. [CrossRef]

39. Luo, C.; Guldi, D.M.; Imahori, H.; Tamaki, K.; Sakata, Y. Sequential energy and electron transfer in an artificial reaction center: Formation of a long-lived charge-separated state. J. Am. Chem. Soc. 2000, 122, 6535-6551. [CrossRef]

40. Imahori, H.; Tamaki, K.; Guldi, D.M.; Luo, C.; Fujitsuka, M.; Ito, O.; Fukuzumi, S. Modulating charge separation and charge recombination dynamics in porphyrin-fullerene linked dyads and triads: Marcus-normal versus inverted region. J. Am. Chem. Soc. 2001, 123, 2607-2617. [CrossRef]

41. Imahori, H.; Guldi, D.M.; Tamaki, K.; Yoshida, Y.; Luo, C.; Sakata, Y.; Fukuzumi, S. Charge separation in a novel artificial photosynthetic reaction center lives 380 ns. J. Am. Chem. Soc. 2001, 123, 6617-6628. [CrossRef] [PubMed]

42. Imahori, H.; Sekiguchi, Y.; Kashiwagi, Y.; Sato, T.; Araki, Y.; Ito, O.; Fukuzumi, S. Long-lived charge-separated state generated in a ferrocene-meso,meso-linked porphyrin trimer-fullerene pentad with a high quantum yield. Chem. Eur. J. 2004, 10, 3184-3196. [CrossRef] [PubMed]

43. Vecchi, A.; Galloni, P.; Floris, B.; Dudkin, S.V.; Nemykin, V.N. Metallocened meet porphyrinoid: Consequences of a "fusion". Coord. Chem. Rev. 2015, 291, 95-171. [CrossRef]

44. Curiel, D.; Ohkubo, K.; Reimers, J.R.; Fukuzumi, S.; Crossley, M.J. Photoinduced electron transfer in $\beta$, $\beta^{\prime}$-pyrrolic fused ferrocene-(zinc porphyrin)-fullerene. Phys. Chem. Chem. Phys. 2007, 9, 5260-5266. [CrossRef] [PubMed]

45. Mazzuca, C.; Di Napoli, B.; Lentini, S.; Cicero, D.O.; Gatto, E.; Tagliatesta, P.; Palleschi, A. $\beta$-substituted ferocenyl porphyrins: The role of the spacer and of the number of substituents on their structural and spectroscopic characteristics. J. Porphyr. Phthalocyanines 2016, 20, 234-244. [CrossRef]

46. Tagliatesta, P.; Pizzoferrato, R. Synthesis and characterization of new ferrocene, porphyrin and $\mathrm{C}_{60}$ triads, connected by triple bonds. J. Organomet. Chem. 2015, 787, 27-32. [CrossRef]

47. Limosani, F.; Possanza, F.; Ciotta, E.; Pepi, F.; Salvitti, C.; Tagliatesta, P.; Pizzoferrato, R. Synthesis and characterization of two new triads with ferrocene and C60 connected by triple bonds to the beta-positions of meso-tetraphenylporphyrin. J. Porphyr. Phthalocyanines 2017, 21, 364-370. [CrossRef]

48. Possanza, F.; Limosani, F.; Tagliatesta, P.; Zanoni, R.; Scarselli, M.; Ciotta, E.; Pizzoferrato, R. Functionalization of carbon spheres with a porphyrin-ferrocene diad. Chem. Phys. Chem. 2018, 19, 2243-2249. [CrossRef]

49. Scarselli, M.; Limosani, F.; Passacantando, M.; D’Orazio, F.; Nardone, M.; Cacciotti, I.; Arduini, F.; Gautron, E.; De Crescenzi, M. Influence of iron catalyst in the carbon spheres synthesis for energy and electrochemical applications. Adv. Mater. Interfaces 2018, 5, 1800070. [CrossRef] 
50. Cinti, S.; Limosani, F.; Scarselli, M.; Arduini, F. Magnetic carbon spheres and their derivatives combined with printed electrochemical sensors. Electrochim. Acta 2018, 282, 247-254. [CrossRef]

51. Kaur, R.; Possanza, F.; Limosani, F.; Bauroth, S.; Zanoni, R.; Clark, T.; Arrigoni, G.; Tagliatesta, P.; Guldi, D.M.J. Understanding and controlling short- and long-range electron/charge transfer processes in electron donor-acceptor conjugates. J. Am. Chem. Soc. 2020, 142, 7898-7911. [CrossRef]

52. Limosani, F.; Kaur, R.; Cataldo, A.; Bellucci, S.; Micciulla, F.; Zanoni, R.; Lembo, A.; Wang, B.; Pizzoferrato, R.; Guldi, D.M.; et al. Designing cascades of electron transfer processes in multicomponent graphene conjugates. Angew. Chem. Int. Ed. 2020, 59, 23706-23715. [CrossRef]

53. Tagliatesta, P.; Lembo, A.; Leoni, A. Synthesis and characterization of eight new tetraphenylporphyrins bearing one or two ferrocene on the $\beta$-pyrrole positions. New J. Chem. 2013, 37, 3416-3419. [CrossRef]

54. Willets, A.; Rice, J.E.; Burland, D.M.; Shelton, D.P.J. Problems in the comparison of theoretical and experimental hyperpolarizabilities. Chem. Phys. 1992, 97, 7590-7599. [CrossRef]

55. Frisch, M.J.; Trucks, G.W.; Schlegel, H.B.; Scuseria, G.E.; Robb, M.A.; Cheeseman, J.R.; Scalmani, G.; Barone, V.; Petersson, G.A.; Nakatsuji, H.; et al. Gaussian 16, Revision A.03; Gaussian, Inc.: Wallingford, CT, USA, 2016.

56. Ernzerhof, M.; Scuseria, G. Assessment of the Perdew-Burke-Ernzerhof exchange-correlation functional. J. Chem. Phys. 1999, 110, 5029-5036. [CrossRef]

57. Adamo, C.; Barone, V. Toward reliable density functional methods without adjustable parameters: The PBE0 model. J. Chem. Phys. 1999, 110, 6158-6169. [CrossRef]

58. Scalmani, G.; Frisch, M.J. Continuous surface charge polarizable continuum models of solvation. I. General formalism. J. Chem. Phys. 2010, 132, 114110. [CrossRef] [PubMed]

59. Zhao, Y.; Truhlar, D.G. The Mo6 suite of density functionals for main group thermochemistry, thermochemical kinetics, noncovalent interactions, excited states, and transition elements: Two new functionals and systematic testing of four Mo6-class functionals and 12 other functionals. Theor. Chem. Acc. 2008, 120, 215-241. [CrossRef]

60. Johnson, L.E.; Dalton, L.R.; Robinson, B.H. Optimizing calculations of electronic excitations and relative hyperpolarizabilities of electrooptic chromophores. Acc. Chem. Res. 2014, 47, 3258-3265. [CrossRef] [PubMed]

61. Kurtz, H.A.; Dudis, D. Quantum mechanical methods for predicting nonlinear optical properties. Rev. Comput. Chem. 2007, 12, 241-279. [CrossRef]

62. Pielak, K.; Tonnelé, C.; Sanguinet, L.; Cariati, E.; Righetto, S.; Muccioli, L.; Castet, F.; Champagne, B. Dynamical behaviour and second harmonic generation responses in acido-triggered molecular switches. J. Phys. Chem. C 2018, 122, 26160-26168. [CrossRef]

63. Xiao, X.; Nagahara, L.A.; Rawlett, A.M.; Tao, N. Electrochemical gate-controlled conductance of single oligo(phenylene ethynylene)s. J. Am. Chem. Soc. 2005, 127, 9235-9240. [CrossRef]

64. Lewis, P.A.; Inman, C.E.; Maya, F.; Tour, J.M.; Hutchinson, J.E.; Weiss, P.S. Molecular engineering of the polarity and interactions of molecular electronic switches. J. Am. Chem. Soc. 2005, 127, 17421-17426. [CrossRef]

65. Huber, R.; Gonzalez, M.T.; Wu, S.; Langer, M.; Grunder, S.; Horhoiu, V.; Mayor, M.; Bryce, M.R.; Wang, C.; Jitchati, R.; et al. Electrical conductance of conjugated oligomers at the single molecule level. J. Am. Chem. Soc. 2008, 130, 1080-1084. [CrossRef]

66. Di Carlo, G.; Orbelli Biroli, A.; Pizzotti, M.; Tessore, F.; Trifiletti, V.; Ruffo, R.; Abbotto, A.; Amat, A.; De Angelis, F.; Mussini, P.R. Tetraaryl $\mathrm{Zn}^{\mathrm{II}}$ porphyrinates substituted at $\beta$-pyrrolic positions as sensitizers in dye-sensitized solar cells: A comparison with meso-disubstituted push-pull Zn(II) porphyrinates. Chem. Eur. J. 2013, 19, 10723-10740. [CrossRef] [PubMed]

67. Liang, Y.; Xie, Y.-X.; Li, J.-H. Modified palladium-catalyzed sonogashira cross-coupling reactions under copper-, amine-, and Solvent-Free Conditions. J. Org. Chem. 2005, 71, 379-381. [CrossRef] [PubMed]

68. Lindsey, J.S.; Prataphan, S.; Johnson, T.E.; Wagner, R.W. Porphyrin building blocks for modular construction of bioorganic model systems. Tetrahedron 1994, 50, 8941-8968. [CrossRef]

69. Wagner, R.W.; Johnson, T.E.; Lindsey, J.S. Soluble synthetic multiporphyrin arrays. 1. modular design and synthesis J. Am. Chem. Soc. 1996, 118, 11166-11180. [CrossRef]

70. Wagner, R.W.; Johnson, T.E.; Li, F.; Lindsey, J.S. Synthesis of ethyne-linked or butadiyne-linked porphyrin arrays using mild, copper-free, Pd-mediated coupling reactions. J. Org. Chem. 1995, 60, 5266-5273. [CrossRef]

71. Maggini, M.; Scorrano, G.; Prato, M. Addition of azomethine ylides to C60: Synthesis, characterization, and functionalization of fullerene pyrrolidines. J. Am. Chem. Soc. 1993, 115, 9798-9799. [CrossRef]

72. Gouterman, M. Spectra of porphyrins. J. Mol. Spectrosc. 1961, 6, 138-163. [CrossRef]

73. Kumar, S.; Acharyya, J.N.; Banerjee, D.; Soma, V.R.; Prakash, G.V.; Sankar, M. Strong two-photon absorption and ultrafast dynamics of meso-functionalized "push-pull" trans-A 2 BC porphyrins. Dalton Trans. 2021, 50, 6256-6272. [CrossRef] [PubMed]

74. Orbelli Biroli, A.; Tessore, F.; Vece, V.; Di Carlo, G.; Mussini, P.R.; Trifiletti, V.; De Marco, L.; Giannuzzi, R.; Manca, M.; Pizzotti, M. Highly improved performance of $\mathrm{Zn}^{\mathrm{II}}$ tetraarylporphyrinates in DSSCs by the presence of octyloxy chains in the aryl rings. $J$. Mater Chem. A 2015, 3, 2954-2959. [CrossRef]

75. Prato, M.; Soombar, C.; Vazquez, E.; Niziol, J.; Gondek, E.; Rau, I.; Kajar, F. Synthesis and spectroscopic properties of porphyrin derivatives of C60. Mol. Cryst. Liq. Cryst. 2010, 521, 253-264. [CrossRef] 
76. Di Carlo, G.; Orbelli Biroli, A.; Tessore, F.; Rizzato, S.; Forni, A.; Magnano, G.; Pizzotti, M. Light-induced regiospecific bromination of meso-tetra(3,5-di-tert-butylphenyl)porphyrin on 2, $12 \beta$-pyrrolic positons. J. Org. Chem. 2015, 80, 4973-4980. [CrossRef] [PubMed]

77. Oudar, J.L.; Chemla, D.S. Hyperpolarizabilities of the nitroanilines and their relations to the excited state dipole moment. J. Chem. Phys. 1977, 66, 2664-2668. [CrossRef]

78. Oudar, J.L. Optical nonlinearities of conjugated molecules. Stilbene derivatives and highly polar aromatic compounds. J. Chem. Phys. 1977, 67, 446-457. [CrossRef]

79. Kanis, D.R.; Lacroix, P.G.; Ratner, M.A.; Marks, T.J. Electronic structure and quadratic hyperpolarizabilities in organotransitionmetal chromophores having weakly coupled p-networks. Unusual mechanism for second-order response. J. Am. Chem. Soc. 1994, 116, 10089-10102. [CrossRef]

80. Dragonetti, C.; Colombo, A.; Fontani, M.; Marinotto, D.; Nisic, F.; Righetto, S.; Roberto, D.; Tintori, F.; Fantacci, S. Novel fullerene alkynyl complexes with high second-order nonlinear optical properties as a springboard for NLO-active polymer films. Organometallics 2016, 35, 1015-1021. [CrossRef]

81. Pizzotti, M.; Ugo, R.; Annoni, E.; Quici, S.; Ledoux-Rak, I.; Zerbi, G.; Del Zoppo, M.; Fantucci, P.; Invernizzi, I. A critical evaluation of EFISH and THG non-linear optical responses of asymmetrically substituted meso-tetraphenyl porphyrins and their metal complexes. Inorg. Chim. Acta 2002, 340, 70-80. [CrossRef]

82. De La Torre, G.; Vazquez, P.; Agullo-Lopez, F.; Torres, T. Role of structural factors in the nonlinear optical properties of phtalocyanines and related Compounds. Chem. Rev. 2004, 104, 3723-3750. [CrossRef]

83. Belviso, S.; Santoro, E.; Penconi, M.; Righetto, S.; Tessore, F. Thioethylporphyrazines: Attractive chromophores for second order nonlinear optics and DSSCs. J. Phys. Chem. C 2019, 123, 13074-13082. [CrossRef] 